\title{
Competências profissionais e interdisciplinaridade no Direito: percepções de discentes de uma faculdade particular mineira
}

\author{
Kely César Martins de Paiva \\ Fernando Procópio Lage \\ Sthefania Navarro dos Santos \\ Carla Ribeiro Volpini Silva \\ Faculdade Novos Horizontes
}

\section{Resumo}

0 objetivo deste estudo foi descrever e analisar as contribuições do curso superior de Direito, de maneira geral, e de uma prática pedagógica interdisciplinar, em particular, na formação e no desenvolvimento de competências profissionais nos alunos de uma instituição de ensino superior privada mineira, na percepção dos próprios discentes. 0 referencial teórico divide-se em três partes: competência profissional; interdisciplinaridade e interdisciplinaridade no Direito; diretrizes curriculares nacionais para o curso de graduação em Direito. Na pesquisa de campo, descritiva e de natureza quantitativa e qualitativa, os dados foram coletados, prioritariamente, por meio de um questionário aplicado aos alunos do curso. Na apresentação e análise dos dados, caracterizaramse as percepções dos discentes quanto ao nível de contribuição do curso e da prática interdisciplinar na formação de suas competências profissionais a partir de duas bases conceituais (o modelo de competências de Maria Teresa Fleury e Afonso Fleury e as competências previstas nas diretrizes curriculares nacionais), além de seus comentários e sugestões. Observou-se um nível considerado satisfatório de tais contribuições na percepção dos respondentes, porém, com percalços a serem enfrentados, pessoal e institucionalmente, principalmente quanto à participação dos próprios alunos e dos professores. Diante das limitações percebidas neste estudo, foram sugeridos outros passos investigativos com vistas a aprofundar e ampliar os achados.

\section{Palavras-chave}

Competência profissional - Interdisciplinaridade - Direito - Ensino superior - Ensino jurídico. 


\section{Professional competences and interdisciplinarity in Law: perceptions from students of a private college in Minas Gerais}

Kely César Martins de Paiva

Fernando Procópio Lage

Sthefania Navarro dos Santos

Carla Ribeiro Volpini Silva

Novos Horizontes College

Contact:

Kely César Martins de Paiva

Rua Alvarenga Peixoto, 1270

30180-121 - Belo Horizonte/MG

E-mail: kely.paiva@unihorizontes.br

\begin{abstract}
The objective of this study was to describe and analyze the contributions of the higher education in Law in general, and of an interdisciplinary pedagogical practice in particular, to the formation and development of professional competences in the students of a private institution of higher education in Minas Gerais, in the perspective of the students themselves. The theoretical framework is divided into three parts: professional competence; interdisciplinarity and interdisciplinarity in Law; national curriculum guidelines for the Law course. In the fieldwork, descriptive and of quantitative and qualitative character, data were collected primarily from a questionnaire applied to the students. In presenting and analyzing the data, the perceptions of the students were characterized as to the level of contribution of the course and of the interdisciplinary practice in the formation of their professional competences, based on two conceptual references (the competences model by Maria Teresa Fleury and Afonso Fleury, and the competences prescribed by the national curriculum guidelines), apart from their comments and suggestions. The level of contribution thus observed was considered satisfactory in the perspective of the respondents; however, challenges were identified, personally and institutionally, especially concerning the participation of the students and of the teachers. In view of the limitations observed in this study, other investigation steps were suggested with the purpose of deepening and widening these findings.
\end{abstract}

\section{Keywords}

Professional competence - Interdisciplinarity - Law - Higher education - Law education. 
Diante dos processos de reestruturação produtiva, da crescente flexibilização das relações de trabalho e dos mercados mais exigentes, a sociedade carece de profissionais mais bem formados e informados, com habilidades distintas, rapidez e efetividade nos processos de tomada de decisão. Para tanto, é primordial o papel da educação e, em especial, da educação em nível superior. Para Neisser Freitas (2000),

\section{[...] a educação deve ser trabalhada na ex- pressão de formar cidadãos críticos e cons- cientes que, em decorrência desta percepção, possam em uma primeira etapa se pensarem enquanto seres de cultura e agentes trans- formadores buscando assim mudarem-se a si próprios e, em seguida, influenciarem as pessoas e o meio em que vivem (p. 2)}

alicerçando essa perspectiva em uma base ideária transformista. No caso específico do Direito, Freitas (2000) destaca sua "notória expressão social e política" (p. 2), tendo em vista a inserção de seus profissionais na sociedade no decorrer da história do país. Quanto aos cursos de Direito, Floricea Martins (2005) afirma que

[...] o desafio imediato dos cursos de Direito no país deve passar pela reformulação das políticas pedagógicas estabelecendo um novo paradigma, capaz de romper com o tradicional modelo positivista e formar profissionais humanistas dentro de uma abordagem interdisciplinar aptos a compreender e mensurar os fenômenos jurídicos e suas implicações sociais, utilizar as técnicas e aliar a teoria à prática. (p. 3)

A autora pauta-se em Norberto Bobbio, quando este sublinha a carência de um estudo interdisciplinar do Direito, já que o estudo da norma jurídica não pode desprezar o conjunto coordenado, suas interfaces e intrarrelações, colocando em discussão o caráter positivista do ensino jurídico. Nesse sentido, Martins (2005) afirma que as diretrizes positivistas refletem-se nas práticas pedagógicas e nos conteúdos dos currículos, constituindo-se como entraves para a formação do bacharel em Direito no país. Essa percepção é comungada por outros autores, como Marta de Sousa e Heloisa Helena de Azevedo (2007).

Considerando o aumento da oferta de cursos de graduação em Direito no país após a Lei de Diretrizes e Bases da Educação Nacional, em 1996, e a precariedade a que essa formação tem-se sujeitado, conforme apontado por Freitas (2000), a discussão em torno da formação de competências profissionais do bacharel em Direito entra em uma agenda de pesquisa interdisciplinar, principalmente no que se refere aos campos da Pedagogia, do Direito e da Administração. Segundo Anderson Sant'Anna (2008), o conceito de competência não é novo, pois constitui uma ideia já utilizada em tempos remotos; contudo, ele é redefınido e reavaliado nos dias atuais em virtude da nova ordem mundial, que considera a descontinuidade e a imprevisibilidade como presentes no mundo do trabalho e atribui às competências o papel de elemento chave no processo de sobrevivência individual, coletivo e organizacional.

Nessa ótica, Enio Rezende (2004) sublinha que a competência só se efetiva, tanto no âmbito pessoal como no organizacional, se for aplicada. Assim, só é possível discutir a questão da competência profissional em face dos resultados concretos e positivos, frutos de aprendizagens de naturezas e conteúdos diversos, incluindo, portanto, a questão da interdisciplinaridade como aspecto central. Observe-se o comentário de Fernando Coelho (2001):

Em sintese, enquanto a complexidade e as mudanças se tornam características peculiares de nossa sociedade, a flexibilidade transforma-se em dimensão essencial. A estabilidade em um posto específico de trabalho é substituída pela estabilidade no emprego dentro da empresa, no melhor dos casos. 
A ocupação paulatinamente independe da profissão. A formação especialista requer toques generalistas. A interdisciplinaridade é revalorizada. (p. 6)

Considerando que o curso de graduação em Direito visa atender a um público com expectativas que variam no tempo e no espaço, deve-se possibilitar um aprendizado não apenas formativo no sentido técnico-operacional, mas que também contribua no desenvolvimento de competências profissionais que atendam, posteriormente, à sociedade em suas diversas instâncias. Desse modo, conforme afirmam Doroteu Zimiani e Márcio Hoeppner (2008),

Os cursos de Direito devem se utilizar de instrumentos de ensino que ampliem a consciência de seus alunos para que estejam preparados para entender em que contexto vão operar e o sentido de sua ação na sociedade. (p. 104)

A necessidade de aliar o conhecimento à prática nas faculdades de Direito torna-se algo premente que faz parte da rotina dos estudantes. É comum observar o trânsito que se cria entre as salas de aula e os escritórios de advocacia, gabinetes de juízes ou promotores, ambientes tão ou mais frequentados pelos estudantes que o próprio curso em determinados momentos da vida acadêmica. Esta é, hoje, uma realidade no Brasil: em muitos casos, não podendo o estudante arcar com as despesas do ensino superior, ele é obrigado a trabalhar e a estudar, concomitantemente, a fim de garantir seu sustento enquanto não obtém o diploma.

Diante desse contexto, o objetivo deste artigo é descrever e analisar a contribuição do curso de Direito, de modo geral, e de uma prática pedagógica interdisciplinar, em especial, na formação e no desenvolvimento de competências profissionais nos alunos em uma instituição de ensino particular mineira, na percepção dos próprios discentes. Inicia-se a reflexão a partir do tema da competência profissional, passando pela questão da interdisciplinaridade e da interdisciplinaridade no Direito, e esclarecendo as diretrizes curriculares nacionais para o curso de graduação na área. Após explicitada a metodologia utilizada, os dados coletados foram apresentados e analisados, permitindo que considerações fossem sublinhadas. Ao final, foram apontadas questões relacionadas à prática interdisciplinar, além de possibilidades de pesquisas posteriores, tendo em vista aspectos centrais e operacionais acerca da interdisciplinaridade no ensino superior.

Convém ressaltar que, na região onde se localiza a instituição de ensino superior (IES) na qual se desenvolveu a pesquisa - região metropolitana de Belo Horizonte, Minas Gerais, RMBH-MG -, cursos de graduação em Direito têm sido amplamente oferecidos por várias faculdades; no entanto, apenas três instituições privadas realizam um trabalho acadêmico dessa natureza, ou seja, incorporam e entendem seu projeto pedagógico como um projeto interdisciplinar. Apesar dos limites de variadas ordens - pedagógicos, acadêmicos e institucionais -, observa-se a importância desta reflexão em termos de avaliar os processos envolvidos e os resultados percebidos pelos atores sociais que participam desse tipo de experiência de aprendizagem, com vistas ao seu aprimoramento e ao ajuste às recomendações e exigências de instituições de interesse coletivo como o Conselho Nacional de Educação e a Ordem dos Advogados do Brasil, dentre outras -, e também à difusão no meio acadêmico.

\section{Sobre competência profissional}

Inicialmente, importa frisar que tanto no mundo do trabalho, como no meio acadêmico, a palavra competência tem assumido diversos significados, pendendo entre características pessoais dos indivíduos e exigências dos cargos ou postos de trabalho, ou ainda focando nos processos ou nos resultados desses. Nesse sentido, Cláudia Bitencourt e Allan Barbosa (2004) alinham 
diversas ênfases que vêm sendo dadas aos conceitos de competência, as quais englobam: valores, aptidão, formação, comportamento, ação, interação, resultado, estratégia, aprendizagem individual, autodesenvolvimento, mobilização etc. Assim, os autores demonstram quão frutífero tem sido esse campo de estudo, o que, por outro lado, implica perspectivas ideológicas diferenciadas.

Na percepção de Guy Le Boterf (1994), a competência está situada na convergência entre a pessoa, sua formação educacional e sua experiência profissional, indicando a importância da aprendizagem a partir de múltiplas fontes. Para o autor, a competência é um saber agir responsável que envolve saber mobilizar, integrar e transmitir conhecimentos, recursos e habilidades em certo contexto profissional, implicando o reconhecimento por terceiros. De forma parecida, Paul Sparrow e Mario Bognanno (1994) concebem competên- cia como um conjunto de atitudes promotoras de agilidade na adaptação do sujeito a um ambiente cada vez menos estável, de uso produtivo do conhecimento, de inovação e de aprendizagem permanentes. Para Philippe Zarifian (1994), competência relaciona-se com diversas capacidades das pessoas: capacidade de assumir iniciativas, de estar além do prescrito, de compreender e dominar situações em constante mutação, de ser responsável e reconhecido por outros.

No Brasil, Maria Teresa Fleury e Afonso Fleury (2001) propõem um conceito considerado por eles como, ao mesmo tempo, abrangente e preciso. Para os autores, competência é “um saber agir responsável e reconhecido, que implica mobilizar, integrar, transferir conhecimentos, recursos, habilidades, que agreguem valor econômico à organização, e valor social ao indivíduo" (p. 21). Tais saberes e seus significados estão explicitados no quadro 1.

Quadro 1 - Saberes que compõem as competências profissionais segundo Fleury e Fleury

\begin{tabular}{|c|c|}
\hline Competência & Significados \\
\hline Saber agir & $\begin{array}{l}\text { - Saber o que faz e por quê. } \\
\text { - Saber julgar, escolher, decidir. }\end{array}$ \\
\hline Saber mobilizar & - Saber mobilizar recursos de pessoas, financeiros, materiais, criando sinergia entre eles. \\
\hline Saber comunicar & $\begin{array}{l}\text { - Compreender, processar, transmitir informações e conhecimentos, assegurando o entendimento da } \\
\text { mensagem pelos outros. }\end{array}$ \\
\hline Saber aprender & $\begin{array}{l}\text { - Trabalhar o conhecimento e a experiência. } \\
\text { - Rever modelos mentais. } \\
\text { - Saber desenvolver-se e propiciar o desenvolvimento dos outros. }\end{array}$ \\
\hline Saber comprometer-se & - Saber engajar-se e comprometer-se com os objetivos da organização. \\
\hline Saber assumir responsabilidades & - Ser responsável, assumindo os riscos e as consequências de suas ações, e ser, por isso, reconhecido. \\
\hline Ter visão estratégica & $\begin{array}{l}\text { - Conhecer e entender o negócio da organização, seu ambiente, identificando oportunidades e } \\
\text { alternativas. }\end{array}$ \\
\hline
\end{tabular}

(Fonte: FLEURY; FLEURY, 2001, p. 22). 
Convém, ainda, discernir entre qualificação e competência. Para tanto, recorre-se a Kely Martins de Paiva (2007), autora que afırma que a qualificação está ligada à organização, ao cargo, é algo estático e absoluto no tempo e no espaço; já o termo competência, para ela, está ligado à profissão, ao indivíduo, é dinâmico e relativo ao contexto em que se desenvolvem as atividades produtivas. 0 modelo de competência profissional desenvolvido pela autora contempla tal construto como composto por componentes de cinco ordens diferentes, a saber: cognitiva (o que o sujeito sabe, relativo a conhecimentos formais), funcional (a aplicação do conhecimento pelo sujeito no exercício de suas tarefas e atribuições profissionais), comportamental (como ele se relaciona com outros sujeitos), ética (os valores que pautam sua atitude e sua ação) e política (como ele se posiciona no trabalho em termos das relações de poder, inerentes às relações humanas). Assim sendo, ela alinha a competência a questões éticas e políticas, indicando que a reflexão sobre o tema inclui tais aspectos. Terezinha Rios (2004) também transcende a dimensão técnica do fazer profissional, enfatizando as dimensões ética e política da ação do educador. Cabe a este romper com determinados círculos viciosos, tal como aponta Norbert Elias (1998):

Quem já está de posse de um certo saber tem dificuldade de imaginar a experiência daqueles que ainda não o possuíam. Quando nós mesmos somos os "felizes proprietários" de um patrimônio de saber que representa um nível superior de síntese, é fácil perdermos de vista a dificuldade experimentada por gerações criadas em meio a símbolos conceituais de um estágio anterior para elaborar e compreender os símbolos do nível de sintese imediatamente superior. (p. 147)

Dessa maneira, o conceito de competência mantém relação direta e indissolúvel com o pensar e o agir ético e interdisciplinar.

\section{Sobre interdisciplinaridade e interdisciplinaridade no Direito}

De acordo com Ivam Peleias et al. (2008),

A cultura contemporânea baseia-se na compartimentalização do saber. A educação acompanha tal fato, tendo em vista que a organização curricular isola as disciplinas como realidades estanques, sem conexão, o que impede a compreensão do conhecimento de forma integrada e, por conseqüência, uma percepção totalizante da realidade. (p. 2)

Devido a seu poder estruturador, a interdisciplinaridade concretiza-se como uma condição fundamental do ensino e da pesquisa na sociedade contemporânea (LEIS, 2001), promovendo a capacitação dos alunos em termos de enfrentar e solucionar problemas na atualidade (SANTOMÉ, 1998). Ela vai além da interdependência entre os vários ramos do conhecimento e pauta-se em uma nova concepção de ensino e currículo (ANDRADE, 1998), sendo conceituada por Hilton Japiassu (1976), Ivani Fazenda (1979) e Basarab Nicolescu (1999) como compartilhamento, interação e relação entre várias disciplinas distintas com objetivo de romper os limites entre os conhecimentos especializados, conforme sublinham Heloísa Lück (1995) e Japiassu (1976).

Alguns autores, como Lück (1995), Ada Dencker (2002) e Fazenda (2002), também percebem a interdisciplinaridade como um ingrediente fundamental para uma compreensão mais ampla e profunda da complexidade da realidade, por meio da superação de uma visão fragmentada de mundo. Ivone Pereira, Leidimar Santos e Ilírio Rech (2008) resumem a discussão e entendem [...] que a interdisciplinaridade constitui uma
proposta de mudança de comportamento
entre docente e discente, em que o profes-
sor auxilia o aluno a construir seus próprios
conhecimentos, capazes de enfrentar as mu-
danças atuais. (p. 3) 
Focalizando o curso em questão, Freitas (2000) afirma que o Direito

[...] não é apenas um ramo do conhecimento científico, mas também é caracterizado tanto pela abstração normativa como pela práxis judiciária que obrigatoriamente impõem vigência às coisas e pessoas que, dizendo de outra forma, geram conseqüências. Por isto, a presente discussão [o ensino jurídico na graduação, no Brasil] deve ser analisada e estudada com bastante propriedade, inclusive pois há uma premência em se definir a cultura científico-jurídica dentro do atual conceito de democracia, cidadania e liberdade. (p. 3)

Segundo o autor, tal cultura tem-se pautado na ambiguidade a respeito do próprio conceito de Direito, alvo privilegiado do ato filosófico, principalmente considerando-se sua demarcação positivista normativa, com todas as consequências que isso pode trazer sobre vários aspectos - desde as práticas pedagógicas até o próprio exercício da profissão. 0 ensino nos moldes tradicionais (atuais) favorece a formação de profissionais desprovidos de massa crítica e que, portanto, manifestam dificuldades de efetivarem-se e de serem reconhecidos como competentes no mercado de trabalho. Observe-se o comentário de Martins (2005):

Em virtude dessas considerações é imperativo compreender que os principais entraves para a realização da teoria e práxis da interdisciplinaridade nos cursos jurídicos, segundo Gustin [e Dias] (2002) passam pelas: resistências colocadas pelos especialistas em Direito; inércia das instituições de ensino, valorizando a herança positivista da especialização e; o apego ao formalismo presente na opção pedagógica da Instituição de Ensino Superior. Outro fator que pode estar relacionado é a própria incom- preensão da etimologia da palavra interdisciplinaridade por parte dos educadores e educandos. (p. 5)

Dessa forma, o pensar e o agir interdisciplinares envolvem mudança de atitude, de postura, conforme salientado por Fazenda (1979) e, no caso específico do Direito, também por Martins (2005). Tal mudança engloba alunos, professores e a própria instituição de ensino, principalmente se se considerar o fundamento legal que rege o funcionamento dos cursos superiores, e impõe-lhes uma série de prerrogativas, a saber, as diretrizes curriculares nacionais para cada curso superior.

\section{Sobre as Diretrizes Curriculares Nacionais do Curso de Gradua- ção em Direito}

De acordo com o artigo $3^{\circ}$ das $D i$ retrizes Curriculares Nacionais do Curso de Graduação em Direito, DCN-CGD , esse curso deve assegurar ao aluno uma formação geral sólida, humanística e axiológica, além de desenvolver suas capacidades relativas à análise, ao domínio de conceitos e da terminologia jurídica, à adequada argumentação, à interpretação e à valorização dos fenômenos jurídicos e sociais, conjugando tudo isso a uma postura reflexiva e crítica que o conduza à aprendizagem contínua, autônoma e dinâmica, indispensável ao exercício da ciência do Direito, da prestação da justiça e do desenvolvimento da cidadania.

No artigo $4^{\circ}$, as diretrizes curriculares prescrevem as seguintes habilidades e competências mínimas a serem reveladas na prática profissional futura do discente:

I. leitura, compreensão e elaboração de textos, atos e documentos jurídicos ou normativos, com a devida utilização das normas técnico-jurídicas;

II. interpretação e aplicação do Direito; 
III. pesquisa e utilização da legislação, da jurisprudência, da doutrina e de outras fontes do Direito;

IV. adequada atuação técnico-jurídica, em diferentes instâncias, administrativas ou judiciais, com a devida utilização de processos, atos e procedimentos;

V. correta utilização da terminologia jurídica ou da Ciência do Direito;

VI. utilização de raciocínio jurídico, de argumentação, de persuasão e de reflexão crítica;

VII. julgamento e tomada de decisões; e,

VIII. domínio de tecnologias e métodos para permanente compreensão e aplicação do Direito. (BRASIL, 2004, p. 2)

Note-se que, no referido artigo, as diretrizes não distinguem conceitualmente entre as habilidades e as competências a serem manifestas no exercício profissional e reconhecidas socialmente, fato que por si só já tem gerado discussões no seio da educação.

\section{Metodologia}

O objetivo deste estudo foi descrever e analisar as contribuições do curso superior de Direito, de maneira geral, e de uma prática pedagógica interdisciplinar, em particular, na formação e no desenvolvimento de competências profissionais nos alunos de uma IES privada mineira, na percepção dos próprios discentes.

Para tanto, optou-se por uma pesquisa descritiva e de campo (VERGARA, 2009), de natureza quantitativa e qualitativa, já que se buscou tanto identificar regularidades na amostra - alunos do curso de Direito - que possam ser estendidas à população - alunos de uma IES particular mineira -, como também apoiar-se num olhar diferenciado sobre a realidade investigada, o qual é designado por Pedro Demo (2002) como uma visão ampliada.

Sobre a relação população-amostra, convém sublinhar alguns detalhes importantes.
Quando da coleta de dados, o total de alunos do curso de Direito era 443. Discentes de todos os períodos em andamento na IES (do $2^{\circ}$ ao $7^{\circ}$ ) participaram da amostra, desconsiderando-se 70 alunos do $1^{\circ}$ período, já que estes estavam passando pela primeira produção do trabalho interdisciplinar (TI), que é o resultado final do projeto interdisciplinar (PI) desenvolvido semestralmente na IES. Dentre os 373 alunos restantes, foram distribuídos e recolhidos 171 questionários, os quais compuseram a amostra total final. Desse modo, a amostragem deu-se por acessibilidade (VERGARA, 2009); o questionário foi entregue nas salas de aula e aguardou-se por seu preenchimento. Quando dessa entrega, os alunos foram orientados no sentido de que não se tratava de um formulário de avaliação institucional e que suas respostas seriam mantidas em sigilo e subsidiariam a elaboração de um artigo acadêmico.

Tal questionário foi o principal instrumento de coleta de dados e desdobrou-se em quatro partes: a primeira incluiu dados demográficos, acadêmicos e profissionais dos alunos respondentes; a segunda parte continha 25 afirmativas, sendo que 17 versavam sobre a relação do curso, de uma maneira geral, e do trabalho interdisciplinar, em especial, com o desenvolvimento dos diversos saberes apontados no modelo de Fleury e Fleury (2001), e outras 8 com as competências profissionais prescritas nas DCN-CGD (BRASIL, 2004); a terceira parte englobou sete afirmativas que tratavam dos níveis em que tal trabalho contribuiu para diversos aspectos da vida do aluno (pessoal, profissional e acadêmica) e, também, de fatores institucionais de apoio (orientação dos professores envolvidos), de comportamento do grupo de alunos (participação efetiva) e de viabilidade em termos de tempo para sua consecução (durante o semestre); por fım, na quarta parte, disponibilizou-se um espaço para comentários e sugestões. Na segunda e na terceira parte, o nível de concordância foi apontado pelos discentes em uma escala tipo Likert de 5 graus. 
Finalmente, a análise foi realizada da seguinte forma: os dados coletados na primeira, na segunda e na terceira parte do questionário foram tratados estatisticamente, utilizando-se, para tanto, uma planilha eletrônica (Excel); já os dados da quarta parte foram analisados à luz da técnica de análise de conteúdo (BARDIN, 1977).

\section{Apresentação e análise dos dados}

A apresentação e a análise dos dados coletados estão organizadas em cinco itens, a saber: dados demográficos dos respondentes; percepções dos respondentes quanto à contribuição do curso e do projeto interdisciplinar para a formação e o desenvolvimento de saberes e competências segundo o modelo de Fleury e Fleury (2001); percepções dos respondentes quanto à contribuição do curso e do projeto interdisciplinar para a formação e o desenvolvimento das competências prescritas nas DCN-CGD; dados adicionais sobre o trabalho interdisciplinar, na percepção dos alunos; comentários e sugestões dos alunos.

\section{Dados demográficos, acadêmicos e profissionais dos alunos respondentes}

Os dados demográficos, acadêmicos e profissionais dos alunos respondentes foram os seguintes:

a) sexo: a maioria dos alunos respondentes é do sexo masculino (53,8\%);

b) faixa etária: grande parte deles encontra-se abaixo dos 35 anos de idade (55,1\%); abaixo de 25 anos encontram-se $21,1 \%$ do total dos participantes da pesquisa;

c) estado civil: o percentual encontrado em muito se aproximou entre solteiros $(41,5 \%)$ e casados $(42,7 \%)$, sendo que 4,7\% vivem em regime de união estável; d) experiência profissional: os discentes pesquisados mostraram certa maturidade: $32,2 \%$ deles têm acima de 16 anos de experiência; 18,1\% têm acima de 20 anos de experiência; e apenas 13,5\% têm experiência inferior a dois anos;

e) nivel hierárquico ocupado por discentes que trabalham: 28,7\% deles encontram-se no nível operacional; 24,0\% estão no nível gerencial; e, no nível estratégico, esse percentual atinge $36,8 \%$ dos alunos pesquisados;

f) periodo regular no curso de Direito: $28,0 \%$ dos discentes que responderam ao questionário estão cursando $03^{\circ}$ período; 23,4\%, o $5^{\circ}$ período; $17,0 \%$, o $4^{\circ}$ período; $17,0 \%$, o $7^{\circ}$ período; e $14,6 \%$ deles estão no $6^{\circ}$ período.

Assim, sobre os dados demográficos, pode-se afirmar que a maioria dos discentes respondentes é do sexo masculino, com idade inferior a 35 anos; tem mais de dez anos de experiência profissional; encontra-se, nas organizações onde trabalha, em posição gerencial e estratégica; e, na faculdade, estão em diversos períodos do curso, tendo participado de vários TI's.

0 curso de Direito, o trabalho interdisciplinar e os saberes-competências do modelo de Fleury e Fleury (2001)

De maneira geral, os alunos apresentaram percepções consideradas medianas quanto à contribuição do curso de Direito para a formação de suas competências profissionais segundo o modelo de Fleury e Fleury (2001). Apenas dois dos saberes obtiveram avaliação considerada satisfatória: saber aprender $\mathrm{e}$ saber agir (84,2\% e 51,5\%, respectivamente). Não houve nenhuma avaliação insatisfatória que obteve percentual de respondentes superior às avaliações medianas ou satisfatórias. No que tange ao trabalho interdisciplinar, a avaliação mostrou-se semelhante ao curso, de 
uma maneira geral. Ressalte-se que o percentual de insatisfeitos com a contribuição tanto do curso como do TI para o saber mobilizar foi o maior dentre os outros saberes $(37,4 \%$ e $40,4 \%$, respectivamente), e o saber aprender obteve o maior percentual de respondentes satisfeitos com tais contribuições, ou seja, $84,2 \%$ e $81,9 \%$ respectivamente.

Observando-se individualmente os saberes que compõem a competência profissional no modelo teórico adotado, os níveis de satisfação dos discentes com as contribuições do curso e do TI podem ser resumidos da seguinte forma:

a) saber agir: o percentual de alunos respondentes que indicaram nível satisfatório quanto às contribuições do curso e do TI para este saber foi maioria: $51,4 \%$ e $45,6 \%$, respectivamente, sendo acompanhados daqueles que indicaram níveis medianos de contribuição (39,2\% e 29,8\%, respectivamente);

b) saber mobilizar: níveis medianos de contribuições percebidas pelos alunos predominaram neste saber, tendo sido indicados por $45,0 \%$ e $43,9 \%$ deles para o curso e para o TI, respectivamente, seguidos de níveis insatisfatórios já mencionados, denotando problemas que os alunos enfrentam quanto à aprendizagem acerca da mobilização de recursos de toda ordem, inclusive de seus próprios esforços, para consecução de suas atividades;

c) saber comunicar: o percentual de alunos respondentes que indicaram nível mediano quanto às contribuições do curso e do TI para este saber foi maioria: 41,5\% e $39,8 \%$, respectivamente, sendo acompanhados de 33,9\% daqueles que indicaram níveis insatisfatórios de contribuição do TI e níveis satisfatórios de contribuição do curso (32,7\% deles);

d) saber aprender: como já mencionado, obteve o maior nível de percepções satisfatórias por parte dos alunos em ambas as possibilidades de contribuição, destacan- do-se sensivelmente dos demais saberes, o que pode ser preocupante por um lado, mas consolador de outro, pois indica que o aprender a aprender, prescrito nas DCN-CGD e substancial para o desenvolvimento da interdisciplinaridade, está sendo agregado aos conhecimentos dos discentes, tanto pelo curso como pelo TI;

e) saber comprometer-se: níveis medianos de contribuições percebidas pelos alunos predominaram também neste saber, tendo sido indicados por 45,6\% e 35,7\% deles para o curso e para o TI, respectivamente. No caso das contribuições do curso, os resultados foram acompanhados por 31,6\% de respondentes insatisfeitos e, quanto ao TI, a divisão do restante de discentes foi mais homogênea: 32,7\% deles consideram tais contribuições como satisfatórias e 31,6\% como insatisfatórias, indicando falta de consenso a respeito da contribuição do TI com este saber. Tal fato pode ser justificado por dificuldades pessoais de alguns membros do grupo em acompanhar o ritmo, os interesses e o envolvimento de outros mais comprometidos com a consecução do TI;

f) saber assumir responsabilidades: o percentual de alunos respondentes que também indicaram nível mediano quanto às contribuições do curso e do TI para este saber foi maioria: 45,0\% e 49,7\%, respectivamente, sendo acompanhados de 29,2\% daqueles que indicaram níveis satisfatórios de contribuição do curso e níveis insatisfatórios de contribuição do TI (28,7\% deles), corroborando a percepção descrita no saber anterior, tendo em vista que nem todos têm aprendido a assumir responsabilidades na consecução do TI;

g) ter visão estratégica: assim como os outros saberes, o percentual de alunos respondentes que indicaram nível mediano quanto às contribuições do curso e do TI para este saber preponderou: 53,2\% e 
$47,4 \%$, respectivamente, sendo acompanhados daqueles que indicaram níveis insatisfatórios (32,2\% e 31,6\% respectivamente).

Esses e outros dados podem ser visualizados na tabela 1.

De uma maneira geral, as contribuições do curso e do TI foram percebidas como medianas por 39,5\% e 36,7\% dos respondentes, seguidas de níveis satisfatórios que contabilizaram 36,1\% e 35,0\% dos discentes, ambos respectivamente, quanto à formação de competências, tendo como norte o modelo de Fleury e Fleury (2001).

Desse modo, fica nítida a compreensão parcial do que seja o trabalho interdisciplinar dentro do projeto pedagógico - mais amplo desenvolvido pela IES, tanto em termos do processo de consecução do mesmo, fato que envolve esforços de variadas naturezas, como do resultado apresentado para avaliação, denotando a presença de uma fragmentação cognitiva nos discentes respondentes em virtude de o TI fazer parte do próprio curso.

\section{0 curso, 0 trabalho interdisciplinar e as com- petências prescritas nas Diretrizes Curriculares Nacionais do Curso de Graduação em Direito}

Nessa parte da pesquisa, foram consideradas as relações entre as competências e habilidades prescritas nos incisos do artigo $4^{\circ}$ das DCN-CGD e as contribuições do curso, de maneira geral, e do trabalho interdisciplinar, em especial, na percepção dos alunos.

Tabela 1 - Percentual de alunos por nível de satisfação quanto à contribuição do curso (em geral) e do TI (em particular) para a formação e o desenvolvimento dos saberes-competências do modelo de Fleury e Fleury (2001), na percepção dos discentes

\begin{tabular}{|c|c|c|c|c|}
\hline \multirow[t]{2}{*}{ Competência Profissional } & \multirow{2}{*}{$\begin{array}{l}\text { Âmbito } \\
\text { de } \\
\text { contribuição }\end{array}$} & \multicolumn{3}{|c|}{ Percentual de alunos por nível de satisfação } \\
\hline & & Satisfatório & Mediano & Insatisfatório \\
\hline \multirow[t]{2}{*}{ Saber agir } & Curso & 51,4 & 39,2 & 9,4 \\
\hline & $\mathrm{TI}$ & 45,6 & 29,8 & 24,6 \\
\hline \multirow[t]{2}{*}{ Saber mobilizar } & Curso & 17,5 & 45,0 & 37,4 \\
\hline & $\mathrm{TI}$ & 15,8 & 43,9 & 40,4 \\
\hline \multirow{2}{*}{ Saber comunicar } & Curso & 32,7 & 41,5 & 25,7 \\
\hline & $\mathrm{TI}$ & 26,3 & 39,8 & 33,9 \\
\hline \multirow[t]{2}{*}{ Saber aprender } & Curso & 84,2 & 7 & 8,8 \\
\hline & $\mathrm{TI}$ & 81,9 & 10,5 & 7,6 \\
\hline \multirow[t]{2}{*}{ Saber comprometer-se } & Curso & 22,8 & 45,6 & 31,6 \\
\hline & $\mathrm{TI}$ & 32,7 & 35,7 & 31,6 \\
\hline \multirow[t]{2}{*}{ Saber assumir responsabilidades } & Curso & 29,2 & 45,0 & 25,7 \\
\hline & $\mathrm{TI}$ & 21,6 & 49.7 & 28,7 \\
\hline \multirow[t]{2}{*}{ Ter visão estratégica } & Curso & 14,6 & 53,2 & 32,2 \\
\hline & $\mathrm{TI}$ & 21,1 & 47,4 & 31,6 \\
\hline \multirow[t]{2}{*}{ Geral } & Curso & 36,1 & 39,5 & 24,4 \\
\hline & $\mathrm{TI}$ & 35,0 & 36,7 & 28,3 \\
\hline
\end{tabular}

(Fonte: dados da pesquisa). 
Note-se que as contribuições do curso para a formação e o desenvolvimento das competências prescritas nos incisos I e II - que versam sobre o desenvolvimento da capacidade de leitura, compreensão e elaboração de textos e outros documentos inerentes ao processo técnico-jurídico, bem como sobre a contribuição para interpretação e aplicação do Direito - foram as que obtiveram maior nível de satisfação dentre os respondentes: 75,4\% e 74,3\% de satisfeitos com o curso e $69,0 \%$ e $69,6 \%$ com o TI, para os respectivos incisos.

0 inciso III refere-se ao incentivo à promoção da pesquisa da legislação, da jurisprudência e de outras fontes do Direito, e é o único inciso em que os satisfeitos com o TI superam, mesmo que discretamente, a contribuição do curso: $69,6 \%$ de respondentes satisfeitos com a contribuição do TI para a formação dessa competência e 69,0\% para o curso. Isso indica um ponto de aprofundamento investigativo, já que os demais resultados seguiram outra tendência.

Visando à adequação da atuação técnico-jurídica, com a devida utilização de proces- sos, atos e procedimentos, o inciso IV teve avaliação satisfatória dos respondentes, representando $69,0 \%$ deles para o curso e 64,9\% para o TI.

No caso dos incisos V e VI, que ressaltam, respectivamente, a correta utilização das terminologias jurídicas e a promoção da utilização de raciocínio jurídico, de argumentação, persuasão e reflexão crítica, o percentual dos satisfeitos seguiu a referida tendência, apresentando respostas favoráveis em 67,8\% dos respondentes quando perguntados sobre as contribuições do curso, somados a 62,6\% e 64,3\% deles para as do TI.

Por fim, nos casos dos incisos VII, que enfatiza o julgamento e a tomada de decisões, e VIII, que instiga o domínio de tecnologias e métodos para permanente compreensão e aplicação do Direito, estes foram os que apresentaram menor índice de satisfação pelos discentes no tocante ao TI, com resultados percentuais como 59,1\% e $55,6 \%$, respectivamente. $\mathrm{Na}$ avaliação das contribuições do curso, os percentuais foram de $67,8 \%$ e $65,5 \%$, respectivamente.

A tabela 2 exibe estes e os demais achados.

Tabela 2 - Percentual de alunos por nível de satisfação quanto à contribuição do curso (em geral) e do TI (em particular) para a formação e o desenvolvimento das competências prescritas nas DCN-CGD (BRASIL, 2004), na percepção dos discentes .

\begin{tabular}{|c|c|c|c|c|}
\hline \multirow{2}{*}{$\begin{array}{c}\text { Competências } \\
\text { prescritas nos } \\
\text { incisos das } \\
\text { DCN-CGD }\end{array}$} & \multirow{2}{*}{$\begin{array}{c}\text { Âmbito } \\
\text { de } \\
\text { contribuição }\end{array}$} & \multicolumn{3}{|c|}{ Percentual de alunos por nível de satisfação } \\
\hline & & Satisfatório & Mediano & Insatisfatório \\
\hline \multirow[t]{2}{*}{ I } & Curso & 75,4 & 14,0 & 10,5 \\
\hline & $\mathrm{TI}$ & 69,0 & 14,0 & 17,0 \\
\hline \multirow[t]{2}{*}{$\|$} & Curso & 74,3 & 15,8 & 9,9 \\
\hline & TI & 69,6 & 14,0 & 16,4 \\
\hline \multirow[t]{2}{*}{ III } & Curso & 69,0 & 17,3 & 11,7 \\
\hline & TI & 69,6 & 14,6 & 15,8 \\
\hline \multirow[t]{2}{*}{ IV } & Curso & 69,0 & 19,9 & 11,1 \\
\hline & $\mathrm{TI}$ & 64,9 & 19,3 & 15,8 \\
\hline \multirow[t]{2}{*}{ V } & Curso & 67,8 & 18,1 & 14,0 \\
\hline & $\mathrm{TI}$ & 62,6 & 20,5 & 17,0 \\
\hline \multirow[t]{2}{*}{$\mathrm{Vl}$} & Curso & 67,8 & 18,1 & 14,0 \\
\hline & $\mathrm{TI}$ & 64,3 & 19,3 & 16,4 \\
\hline \multirow[t]{2}{*}{ VII } & Curso & 67,8 & 18,7 & 13,5 \\
\hline & $\mathrm{TI}$ & 59,1 & 21,0 & 19,9 \\
\hline \multirow[t]{2}{*}{ VIII } & Curso & 65,5 & 21,6 & 12,9 \\
\hline & $\mathrm{TI}$ & 55,6 & 24,0 & 20,5 \\
\hline \multirow[t]{2}{*}{ Geral } & Curso & 75,4 & 14,0 & 10,5 \\
\hline & $\mathrm{TI}$ & 69,0 & 14,0 & 17,0 \\
\hline
\end{tabular}

(Fonte: dados da pesquisa). 
De modo geral, os dados apontam para níveis satisfatórios quanto à contribuição do curso e do TI para as competências prescritas nas DCN-CGD, ressaltando-se, mais uma vez, a superioridade dos resultados satisfatórios do curso diante dos do TI: 75,4\% dos respondentes consideram satisfatórias tais contribuições do curso, e 69,0\% deles posicionam-se de forma semelhante em relação ao TI. Sublinhe-se, ainda, a superioridade desses resultados quando comparados com aqueles norteados pelo modelo de competências de Fleury e Fleury (2001), que se aplica a qualquer profissão. Esse fato é preocupante do ponto de vista da interdisciplinaridade, pois reflete uma formação centrada em conhecimentos mais técnicos e específicos e que não está sendo percebida de forma mais ampliada pelos discentes em seus processos formativos.

\section{Dados adicionais sobre o trabalho interdisciplinar}

Quanto aos dados adicionais coletados a respeito do trabalho interdisciplinar, chama-se atenção para a diferença nos níveis de satisfação quanto à participação dos sujeitos envolvidos. A contribuição dos professores que não são responsáveis pelo grupo não foi bem avaliada pelos respondentes e deve ser repen- sada individual, coletiva e institucionalmente, já que se trata de um trabalho interdisciplinar e que envolve todos os atores circunscritos ao processo educativo. Da mesma forma, a participação efetiva de todos os membros do grupo parece enfrentar sérias dificuldades, fato que, por um lado, tem consequências em termos de sobrecarga de trabalho de alguns, e, por outro, deveria gerar desenvolvimento de competências mais voltadas para os âmbitos comportamental e interpessoal, as quais, destaca-se, não fazem parte do escopo de competências traçadas pelas DCN-CGD.

Note-se ainda que a maioria dos respondentes considera ser maior a contribuição do TI para sua vida acadêmica $(61,4 \%)$ do que para sua vida pessoal $(55,6 \%)$ e profissional $(53,8 \%)$, como se estas estivessem desconectadas, o que indica, mais uma vez, fragmentação cognitiva.

Vale ressaltar que o menor índice de aprovação encontra-se no tempo para elaboração, com o percentual de satisfeitos de 48,5\% e de insatisfeitos de $39,2 \%$ dos respondentes. Destaque-se, ainda, o item participação dos membros dos grupos: os satisfeitos representam $49,1 \%$ e os insatisfeitos $45,0 \%$.

Observem-se os demais resultados na tabela 3 .

Tabela 3 - Percentual de alunos por nível de satisfação quanto à contribuição do TI com diversos aspectos, na percepção dos discentes.

\begin{tabular}{|c|c|c|c|}
\hline \multirow{2}{*}{$\begin{array}{l}\text { Outros aspectos } \\
\text { relacionados ao TI }\end{array}$} & \multicolumn{3}{|c|}{ Percentual de alunos por nível de satisfação } \\
\hline & Satisfatório & Mediano & Insatisfatório \\
\hline Colaboração do professor orientador & 69,6 & 7,6 & 22,8 \\
\hline Contribuição do TI para a formação acadêmica & 61,4 & 13,5 & 25,1 \\
\hline Colaboração dos professores no esclarecimento de dúvidas & 56,7 & 10,5 & 32,7 \\
\hline Contribuição do TI para a formação profissional & 53,8 & 19,3 & 26,9 \\
\hline Tempo para elaboração & 48,5 & 12,3 & 39,2 \\
\hline Colaboração do trabalho para vida pessoal & 55,6 & 28,4 & 16,4 \\
\hline Participação ativa dos membros do grupo & 49,1 & 5,8 & 45,0 \\
\hline
\end{tabular}

(Fonte: dados da pesquisa). 
Diante dos dados expostos, pode-se afirmar que o projeto interdisciplinar desenvolvido no curso de Direito constitui-se em uma atividade percebida pelos alunos de maneira satisfatória; contudo, tal satisfação mostrou-se relativa e os índices apontam para necessidades de minimizar as dificuldades inerentes ao processo, com vistas a assegurar o aprendizado e o desenvolvimento de competências profissionais nos alunos por meio de estratégias pedagógicas diferenciadas, como é o caso do próprio TI.

\section{Comentários e sugestões dos alunos}

No questionário aplicado, foram solicitados comentários e sugestões dos discentes na intenção de conhecer em maior profundidade suas percepções, principalmente em assuntos que o questionário não havia abordado. Alguns itens mencionados pelos alunos merecem destaque:

a) democratizar o planejamento do projeto interdisciplinar e do próprio curso:

A intenção da faculdade com o interdisciplinar é muito boa, mas precisa ser rediscutida e aprimorada. Assim como o curso de Direito tem que procurar novos meios para o desenvolvimento acadêmico dos alunos. (R65)

Nos últimos semestres e, em específico neste, foi observada uma grande desorganização da instituição em relação ao TI Outro fator foi a imposição, no meio do semestre, da forma de avaliação da prova final, sem uma consulta prévia aos interessados, ou seja, os alunos que pagam a mensalidade da faculdade. (R123)

Este questionário foi interessante, pois por meio dele podemos participar das atividades da organização... (R141)

O TI deve ser visto pela organização de forma a promover mais respeito com os alunos; é necessária maior seriedade, os professores precisam respeitar e valorizar mais aquilo que foi feito durante todo o semestre. É preciso mais sociedade. (R169) b) rever os prazos e flexibilizar o tempo de produção e apresentação do TI:

Do inter, a primeira etapa ficou muito próxima do início das aulas, e isso gerou muita confusão na hora de distribuir as tarefas iniciais. (R151)

0 período do inter é muito curto. (R133) $\mathrm{Na}$ apresentação, apresentei em cinco minutos um trabalho de onze páginas e treze anexos, isso é uma incoerência com todo o aprendizado e trabalho que tive para fazer o projeto em cinco meses. (R112)

c) limitar a execução do TI, tendo em vista as demais atividades exigidas no final do curso:

0 projeto interdisciplinar deveria ser desenvolvido somente até o sexto período no máximo. (R23)

Como estamos caminhando para o oitavo período, acho plausível o término do interdisciplinar. (R56)

d) incentivar maior participação dos professores no sentido de promover a motivação e o comprometimento do grupo de alunos:

0 professor orientador deveria fiscalizar os alunos que não participaram da realização do PI e puni-los, evitando a sobrecarga dos que trabalham. [...] 0 PI é um diferencial na faculdade, pena que está sendo banalizado por grande parte dos alunos. (R22)

0 interdisciplinar é muito importante para aprendermos a trabalhar em grupo e também para ativar o espírito de liderança de cada um; porém, não são todos do grupo que pensam da mesma maneira, acontecendo, às vezes, de dois ou três fazerem o trabalho e os outros ficarem esperando para ganhar os pontos. (R57)

Conscientizar os grupos de trabalho do inter para que todos trabalhem em equipe, pois há descompromisso por parte de alguns alunos. (R138) 
e) repensar o TI como uma oportunidade a mais de aprendizagem, que implica a participação mais efetiva de professores e coordenadores, assim como a orientação do corpo docente:

Em relação ao interdisciplinar, que a coordenação seja mais ativa, a coordenação do inter deixa a desejar. Que haja melhor adequação do manual à proposta do inter e que se busque maior comprometimento de alguns professores no dia da banca. (R13)

Duas críticas que tenho a fazer: professor orientador tem que ser mais presente e o professor que corrigir não deve tirar pontos naquilo que o próprio professor orientador indicou ou direcionou a fazer. (R71)

A orientação dos professores a cada trabalho inter tem variado, e nós alunos temos que nos adaptar a cada orientação. Isso dispersa o foco do trabalho. (R149)

Ressalte-se que sete alunos dentre os 171 abordados manifestaram-se contrariamente ao TI, enfatizando outras atividades acadêmicas que, em seu entendimento, são mais importantes para sua formação, ou ainda que esse trabalho seria mais relevante para outros cursos.

Não deveria haver o inter. Somente a monografia e as provas, sobrando, assim, tempo para o aluno ler, estudar, pesquisar, elaborar textos de sua vontade para assim publicá-los. 0 inter, de certa forma, é imposto, não deveria ser desta forma. (R10)

Fim do interdisciplinar. (R48)

Fim do interdisciplinar. (R53)

Fim do interdisciplinar. (R78)

Esta realidade está direcionada para os cursos de área exata, como administração e ciências contábeis. (R127)

Gostaria de sugerir que o interdisciplinar seja abolido da faculdade. Não vejo utilidade nenhuma, só nos deixa triste porque no dia da apresentação é uma arraso (banca). Sugiro que tenha vários simulados, por que aí todos os alunos vêm (nem que seja pra ganhar pontos extras) e isso pode acrescentar muitas coisas no curso de Direito. (R130)

0 trabalho interdisciplinar não tem como objetivo primordial o aprendizado, dias inúteis perdidos com palestras. Acho que deveria ser deletado ou revisto, colocando outras atividades no seu lugar. (R137)

Por fim, diversos alunos exaltam a execução do TI:

0 inter é uma excelente opção para desenvolver no aluno o interesse para a pesquisa. Dar uma oportunidade para o aluno se integrar de maneira objetiva no universo acadêmico. (R41)

Acho o inter um trabalho excelente que realmente desenvolve o pensar, o escrever e o apresentar. Não tenho queixas quanto ao nosso orientador e aos professores do quarto período. (R117)

Tenho a relatar que o curso e o TI estão trabalhando em sintonia, nos ajudando a perder o medo de falar em público, fazendo com que possamos retribuir nossos conhecimentos com os demais colegas. (R171)

Esses dados mostram a diversidade de opiniões dos discentes sobre o curso, sobre o projeto interdisciplinar desenvolvido semestralmente na IES, sobre os processos envolvidos em sua consecução e sobre os resultados percebidos por eles. Os alunos conseguem visualizar, até certo ponto, a amplitude desses aspectos em relação aos sujeitos envolvidos - indo além deles próprios -, bem como suas contribuições para a formação e o desenvolvimento de suas competências profissionais.

\section{Considerações finais}

Diante do objetivo do estudo realizado e dos dados apresentados e analisados, seis considerações merecem destaque:

a) Quanto ao projeto interdisciplinar desenvolvido pela IES, maiores detalhes a respeito de 
seu planejamento e organização mostraram-se necessários para aprofundar a análise dos dados, constituindo uma limitação no estudo que poderá ser sanada em futuras investigações semelhantes.

b) As percepções dos discentes foram, de modo geral, satisfatórias, mas denotam que várias ações corretivas são necessárias, tanto no que tange ao curso, como no que concerne ao projeto interdisciplinar, especificamente. Há uma necessidade premente de estimular os trabalhos coletivos desenvolvidos na IES, despertando a motivação de todos os envolvidos, além de iniciar um processo de conscientização da importância do mesmo e, em última análise, de exclusão daqueles que insistem em manter uma rigidez positivista, conforme mencionado por Martins (2005) e Sousa e Azevedo (2007).

c) Houve certo consenso quanto à discutível participação dos professores na consecução do TI, fato que levanta a questão de postura e de atitude mencionada por Fazenda (1995). Nesse ponto, é importante destacar Rios (2004), autora que aponta a importância do professor no processo de ensino e aprendizagem, já que as dimensões ética e política de sua competência profissional, também salientadas por Paiva (2007), implicam ir além da transmissão de um conteúdo formal, ou seja, da dimensão técnica (RIOS, 2004) ou cognitiva (PAIVA, 2007), preocupando-se com o bem dos demais envolvidos de modo mais amplo, em termos de tempo e espaço.

d) Levando-se em conta os diversos esforços empreendidos pelos alunos na elaboração do trabalho interdisciplinar - reuniões com colegas, pesquisas, redação de texto, contatos com terceiros etc. - e o fato de eles se encontrarem ainda submersos nesse contexto, consideram-se os resultados desse estudo como satisfatórios, advindos de sujeitos cuja percepção seletiva faz-se sensivelmente presente. Por outro lado, tal aspecto pode ser também entendido como outra limitação desta pesquisa, indicando que estudos longitudinais a esse respeito e na IES abordada podem ser elementos frutíferos para revisão e aprimoramento do processo de aprendizagem, não apenas para os alunos, mas também para os professores e para a própria IES, já que esse é seu fim primeiro e o fundamento de sua existência.

e) Há, também, a necessidade de ampliar o diálogo em um nível institucional, no sentido de promover o aprimoramento das próprias diretrizes curriculares do curso focalizado, as quais não diferenciam entre habilidades e competências e, o que talvez seja mais grave, não consideram aspectos comportamentais e políticos quando da delimitação das competências a serem desenvolvidas no alunato. Percebe-se que tais aspectos são substanciais tanto quando se considera uma educação para a emancipação, como quando se visa à adequação ao mercado de trabalho. Respeitando-se tais peculiaridades, caminha-se para uma formação mais distinta dos futuros profissionais e, institucionalmente, contribui-se para seu reconhecimento junto à sociedade. Ou seja, o reconhecimento e a distinção de uma profissão começam no interior das instituições de ensino, as quais se organizam em torno de parâmetros traçados no âmbito do Estado.

f) Especificamente sobre a utilização dos critérios analíticos adotados - ou seja, os presentes no modelo de competências profissionais de Fleury e Fleury (2001) - e das diretrizes curriculares nacionais do curso de graduação em Direito, tal uso, no estudo aqui apresentado, não pressupõe sua aderência total em termos de adequação conceitual às demandas de ordem prática a que se propõem; pelo contrário, esta reflexão coloca-as no centro de um diálogo aberto e em construção, contribuindo para duas discussões complexas, a saber, o caráter (controvertido) da epistemologia do Direito e a própria delimitação do conceito de competência. 
Quanto à interdisciplinaridade, Elias (1998) chama a atenção para tal questão de modo mais amplo:

A tendência de cada grupo de cientistas a considerar sacrossanto o seu próprio campo, como uma espécie de fortaleza protegida dos intrusos por uma muralha de convenções e ideologias profissionais, cria obstáculos a qualquer tentativa de ligar campos científicos diferentes através de um quadro de referência teórico que lhes seja comum. (p. 79)

Tal aspecto aplica-se à epistemologia do Direito e à sua dificuldade em assumir a interdisciplinaridade como algo natural da vida humana e, portanto, da própria ciência, como sublinha Martins (2005).

Já em relação à dificuldade de delimitação do conceito de competência e à luta ideológica que a permeia, Ramos (2001) aponta suas consequências no processo de legitimação de diferenças intraorganizacionais e intraprofissionais, constituindo uma tentativa bem-sucedida, até então, de individualizar uma construção que é, na verdade, coletiva, social.

Diante de tais ponderações, acrescentam-se as seguintes sugestões para investigações futuras: aprofundar a pesquisa na IES, incluindo outros cursos e utilizando uma abordagem predominantemente qualitativa; ampliar a pesquisa a outras IES e a outros cursos, possibilitando comparações e, com isso, a obtenção de mais insumos para o estabelecimento de outros diálogos; abordar outros atores sociais envolvidos, principalmente os docentes, tendo em vista sua corresponsabilidade no processo de aprendizagem; aprofundar as pesquisas a respeito da efetividade das diretrizes curriculares nacionais para o curso de graduação em Direito, assim como outros cursos de graduação, visando ao aprimoramento de tais normas de modo que estas possam aderir às diversificadas demandas contemporâneas, em vários níveis (individuais, profissionais, coletivos, organizacionais, institucionais, sociais etc.).

Quanto aos professores, Zimiani e Hoeppner (2008) afirmam que:

0 papel do professor é de maior importância
para a melhoria do ensino jurídico, espe-
cialmente se utilizar a interdisciplinaridade
para a formação de profissionais, para que
adquiram conhecimento mais integral dos
diversos ramos do Direito. (p. 117)

Acredita-se que investir nessa agenda pode render competências pedagógicas que transcendem o Direito, as quais, por sua vez, podem enraizar-se por todo o ensino superior, vindo a promover ganhos mais amplos para a sociedade - ganhos, de fato, interdisciplinares.

\section{Referências}

ANDRADE, R. M. C. Interdisciplinaridade: um novo paradigma curricular. In: GOULART, I. B. (Org.). A educação na perspectiva construtiva: reflexões de uma equipe interdisciplinar. Petrópolis: Vozes, 1998. p. 93-103.

BARDIN, L. Análise de conteúdo. Lisboa: Edições 70, 1977.

BITENCOURT, C.; BARBOSA, A. C. Q. A gestão de competências. In: BITENCOURT, C. (Org.). Gestão contemporânea de pessoas. Porto Alegre: Bookman, 2004.

BRASIL. Ministério da Educação. Lei no 9.394, de 20 de dezembro de 1996. Estabelece as diretrizes e bases da educação nacional. Diário Oficial da União, Brasília, 1996. 
BRASIL. Resolução CNE/CES nº 9, de 29 de setembro de 2004. Institui as diretrizes curriculares nacionais do curso de graduação em Direito e dá outras providências. Diário Oficial da União, Brasilia, 01 out. 2004. Disponível em: <http://portal.mec.gov.br/cne/ arquivos/pdf/rces09_04.pdf>. Acesso em: jun. 2009.

COELHO, F. S. A educação superior brasileira: convergências e divergências com o mundo do trabalho. In: ENCONTRO NACIONAL DE PÓS-GRADUAÇÃO E PESQUISA EM ADMINISTRAÇÃO, 25., 2001, Campinas. Anais... Campinas: ANPAD, 2001.

DEMO, P. Complexidade e aprendizagem: a dinâmica não linear do conhecimento. São Paulo: Atlas, 2002.

DENCKER, A. F. M. Pesquisa e interdisciplinaridade no ensino superior. São Paulo: Aleph, 2002.

ELIAS, N. Sobre o tempo. Rio de Janeiro: Jorge Zahar, 1998.

FAZENDA, I. C. A. Intregração e interdisciplinaridade no ensino brasileiro: efetividade ou ideologia? São Paulo: Loyola, 1979. . Práticas interdisciplinares na escola. São Paulo: Cortez, 1995.

. Interdisciplinaridade: um projeto em parceria. São Paulo: Loyola, 2002.

FLEURY, A., FLEURY, M. T. L. Estratégias empresariais e formação de competências. São Paulo: Atlas, 2001.

FREITAS, N. O. Ensaio sobre a educação brasileira e o ensino jurídico: 0 ensino jurídico na graduação. Revista OAB Goiás, ano XIV, n. 42, abr./jun. 2000. Disponível em: <http://www.oabgo.org.br/Revistas/42/juridico_42.htm>. Acesso em: jun. 2009.

GUSTIN, M. B. S.; DIAS, M. T. F. Repensando a pesquisa jurídica. Belo Horizonte: Del Rey, 2002.

JAPIASSU, H. Interdisciplinaridade e patologia do saber. Rio de Janeiro: Imago, 1976.

LE BOTERF, G. De la competénce. Paris: Les Editions d'Organization, 1994.

LEIS, H. R. Para uma reestruturação interdisciplinar das ciências sociais: a complexa tarefa de enfrentar os desafios da problemática ambiental sem cair no senso comum da sociedade civil. Ambiente \& Sociedade, Campinas, n. 8, jan./jun., 2001.

LÜCK, H. Pedagogia interdisciplinar. Petrópolis: Vozes, 1995.

MARTINS, F. P. 0 positivismo como obstáculo à interdisciplinaridade no ensino jurídico. jun. 2005. Disponível em: <http:// www.direitonet.com.br/artigos/exibir/2116/0-Positivismo-como-obstaculo-a-interdisciplinaridade-no-ensino-juridico>. Acesso em: jun. 2009.

NICOLESCU, B. 0 manifesto da transdisciplinaridade. São Paulo: Trion, 1999.

PAIVA, K. C. M. Gestão de competências e a profissão docente: um estudo em universidades no Estado de Minas Gerais. 2007, 278 p. Tese (Doutorado em Administração) - Universidade Federal de Minas Gerais, Belo Horizonte, 2007.

PELEIAS, I. R. et al. Pesquisa sobre a percepção da interdisciplinaridade por professores de controladoria em cursos de ciências contábeis no município de São Paulo. In: ENCONTRO NACIONAL DE PÓS-GRADUAÇÃO E PESQUISA EM ADMINISTRAÇÃO, 32., 2008, Rio de Janeiro. Anais... Rio de Janeiro: ANPAD, 2008.

PEREIRA, I. V.; SANTOS, L. C.; RECH, I. J. A interdisciplinaridade no ensino superior da contabilidade no Brasil: um estudo empírico da percepção dos egressos. In: ENCONTRO NACIONAL DE PÓS-GRADUAÇÃO E PESQUISA EM ADMINISTRAÇÃO, 32., 2008, Rio de Janeiro. Anais... Rio de Janeiro: ANPAD, 2008.

RAMOS, M. A pedagogia das competências: autonomia ou adaptação? São Paulo: Cortez, 2001.

REZENDE, E. A força e o poder das competências. São Paulo: Qualitimark, 2004.

RIOS, T. A. Ética e competência. São Paulo: Cortez, 2004. 
SANT'ANNA, A. S. 0 movimento em torno da competência sob uma perspectiva crítica. In: HELAL, D. H.; GARCIA, F. C.; HONORIO, L. C. (Orgs.). Gestão de pessoas e competência: teoria e pesquisa. Curitiba: Juruá, 2008. p. 239-253.

SANTOMÉ, J. T. Globalização e interdisciplinaridade. Porto Alegre: Artes Médicas, 1998.

SOUSA, M. C.; AZEVEDO, H. H. O. Sobre limites e possibilidades da docência no curso bacharelado em Direito. In: MOSTRA ACADÊMICA UNIMEP, 5., 2007, Piracicaba. Anais... Piracicaba: UNIMEP, 2007.

SPARROW, P. R.; BOGNANNO, M. Competency requirement forecasting: issues for international selection and assessment. In: MABEY, C.; ILES, P. (Orgs.) Managing learning. London: Routledge, 1994. p. 57-69.

VERGARA, S. C. Projetos e relatórios de pesquisa em administração. São Paulo: Atlas, 2009.

ZARIFIAN, P. Compétences et organisation qualifiante en milieu industriel. In: MINET, F.; PARLIER, M. ; WITTE, S. La Compétence: mythe, construction ou réalité? Paris: Éditions L’Harmattan, 1994. p. 111-134.

ZIMIANI, D. T.; HOEPPNER, M. G. Interdisciplinaridade no ensino do Direito. Akrópolis, Umuarama, v. 16, n. 2, p. 103-107, abr./ jun. 2008.

Recebido em 29.06.2009

Aprovado em 09.09.2010

Kely César Martins de Paiva é doutora em Administração pela Universidade Federal de Minas Gerais, professora titular e pesquisadora do Programa de Mestrado Acadêmico em Administração da Faculdade Novos Horizontes.

Fernando Procópio Lage é bacharel em Ciências Contábeis e mestre em Administração pelo Programa de Mestrado Acadêmico em Administração da Faculdade Novos Horizontes. E-mail: fernando.lage@seiconsultoria.com.br.

Sthefania Navarro dos Santos é graduanda em Administração pela Faculdade Novos Horizontes e bolsista de Iniciação Científica (FAPEMIG). E-mail: sthefania.santos@unihorizontes.br.

Carla Ribeiro Volpini Silva é doutora em Direito pela Pontifícia Universidade Católica de Minas Gerais, professora titular e coordenadora do Curso de Graduação em Direito da Faculdade Novos Horizontes. E-mail: carla.volpini@unihorizontes.br. 